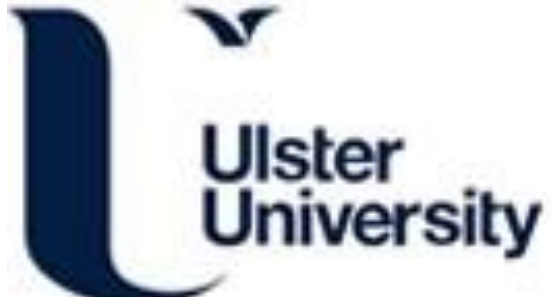

Fire performance of headed shear studs in profiled steel sheeting

Lim, O. K., Choi, S., Choi, J. Y., Kang, S., \& Kim, M. (2019). Fire performance of headed shear studs in profiled steel sheeting. Journal of Constructional Steel Research, 164, [105791].

https://doi.org/10.1016/j.jcsr.2019.105791

Link to publication record in Ulster University Research Portal

Published in:

Journal of Constructional Steel Research

Publication Status:

Published online: 14/11/2019

DOI:

https://doi.org/10.1016/j.jcsr.2019.105791

\section{Document Version}

Author Accepted version

\section{General rights}

Copyright for the publications made accessible via Ulster University's Research Portal is retained by the author(s) and / or other copyright owners and it is a condition of accessing these publications that users recognise and abide by the legal requirements associated with these rights.

\section{Take down policy}

The Research Portal is Ulster University's institutional repository that provides access to Ulster's research outputs. Every effort has been made to ensure that content in the Research Portal does not infringe any person's rights, or applicable UK laws. If you discover content in the Research Portal that you believe breaches copyright or violates any law, please contact pure-support@ulster.ac.uk. 


\title{
Fire Performance of Headed Shear Studs in Profiled Steel
}

\section{Sheeting}

\author{
Ohk Kun Lim ${ }^{a, b, *}$, Sengkwan Choib, , Sungwook Kang ${ }^{c}$, Minjae Kwonc, and J. Yoon \\ Choic
}

${ }^{a} R \& D$ Laboratory, Korea Fire Institute, 331 Jisam-ro, Gyeonggi-do, 17088, Republic of Korea

${ }^{b}$ School of the Built Environment, Ulster University, Newtownabbey, BT37 OQB, UK

cFire Safety Centre, Korea Conformity Laboratories, 73 Yangcheong 3-gil, Cheongju, 28115, Republic of

Korea

\begin{abstract}
The fire performance of shear connections is essential to maintain a composite action in composite beams, for which studies have previously focused on solid slab structures. Despite the popularity of profiled steel sheeting in modern construction, the behaviour of shear studs embedded in transverse deck slabs still needs to be confirmed under elevated temperatures. High-temperature push-out tests were conducted according to the ISO 834 standard fire condition with customised electric furnaces, which showed a failure mode transition with rising temperature. A three-dimensional thermomechanical numerical model was developed and compared with the experimental results for verification. A parametric study revealed that the shear connections were primarily influenced not by the deck thickness or stud welding method but by the temperature distribution, especially around the stud root area.
\end{abstract} Eurocode 4 utilises a thermal degradation factor as well as shear resistance at ambient condition to calculate the load-bearing capacity at fire condition, resulting in a highly conservative

*Corresponding author. Email: terence@kfi.or.kr 
estimation. A better prediction was achieved by omitting the deck reduction factor for stud shearing failure. A new design formula that considers the failure mode transition is thus proposed for a concrete-dominated failure.

Keywords: headed shear stud; trapezoidal deck; push-out test; finite element analysis; fire

\section{Introduction}

Steel and concrete composite structures are widely used in the UK and comprised $66 \%$ of the multi-storey non-residential building market in 2016 [1] because of their many advantages such as large span length, small floor depth, and high stiffness. The material merits are maximised by composite action, which is achieved by shear connections between the steel beams and concrete slabs. A shear connector is a critical component that decides the bearing capacity of a composite structure. Composite beams that use a concrete slab with profiled steel sheeting are commonly utilised in modern construction because the rib deck can be used as a platform for stud welding as well as formwork during concrete casting.

When a supporting beam is oriented in a direction transverse to a trapezoidal deck slab, the shear resistance decreases with regard to deck geometry. Fisher [2] and Grant et al. [3] reported that the shear resistance shows a linear relationship with the dimensional parameter of the deck width to depth; the shear resistance is smaller for a deep deck than wide deck. Several design codes such as AISC360-10 [4] and EC4-1-1 [5] have adopted a configuration factor as the deck reduction parameter to calculate the shear resistance. Qureshi et al. [6] conducted a numerical study to investigate the effects of the stud welding location in a trough and deck thickness on the shear connection. When a headed shear stud was welded in an unfavourable position, the shear resistance increased linearly with deck thickness. Conversely, the effect of the deck 
thickness decreased when the stud location was moved to a favourable position in the rib deck because the failure mode changed from rib punching to concrete pull-out. Numerous experimental and numerical studies have been conducted regarding the characteristics of shear connections in ambient conditions [7-10]. However, to the best of our knowledge, few researchers have addressed the effect of temperature on shear connections, especially with regard to a transverse deck.

The behaviour of headed shear studs under fire condition was initially evaluated by Zhao and Kruppa [11] through high-temperature push-out tests. They observed stud shearing and concrete rib cracking simultaneously in their experiment on transverse deck specimens. However, they only tested two specimens. Mirza et al. [12] carried out push-out tests to evaluate the shear resistance degradation of solid and transverse deck slabs at high temperatures. Stud shearing occurred near the weld collar in the solid slab specimens, while concretedominated failure was observed in the transverse deck specimens. The decrease in the loadbearing capacity of the shear connection from ambient temperature to $600{ }^{\circ} \mathrm{C}$ was $34 \%$ in the solid slab specimen and $41 \%$ in the transverse deck specimen. They argued that these differences in strength reductions were because of different failure modes depending on the concrete slab type. Chen et al. [13] conducted experimental and numerical studies on six specimens incorporating a transverse deck slab at both ultimate limit state (ULS) and fire limit state (FLS). They attached customised heating plates to each specimen, and loading was applied when the stud temperature was increased to a designated value measured $10 \mathrm{~mm}$ above the bottom end of the shear stud; this was because the gas temperature of the experimental setup was different from the ISO 834 standard fire condition [14]. The failure mode changed from concrete rib shearing to stud shearing as the stud temperature increased. All observed failure modes were for stud shearing when the stud temperature exceeded $500{ }^{\circ} \mathrm{C}$. The shear 
resistance was reduced by $31 \%$ at a stud temperature of $600{ }^{\circ} \mathrm{C}$ compared with the ULS value. Differences in strength reductions were observed in comparison to the experimental results of Mirza et al. [12].

The analytical calculation method for shear resistance in the current EC4-1-2 [15] is based on push-out tests with a solid slab specimen [11]. The previous experimental and numerical studies showed different trends for shear resistance in transverse deck applications at high temperatures; one was smaller and the other was larger than the Eurocode guidance $[12,13]$. Therefore, the capacities of shear connections at high temperatures for a transverse deck slab need to be verified. In this study, push-out tests at both ULS and FLS were conducted, and the results were used to validate three-dimensional thermomechanical finite element models. The influences of the deck thickness and welding method on the shear resistance at FLS were considered through parametric studies.

\section{Experimental programme}

\subsection{Specimens and test setup}

The standardised push-out test described in Eurocode is specialised for a solid slab composite beam. It does not provide guidance for a trapezoidal deck specimen and high temperature conditions. Hicks [16] recommended a trapezoidal deck specimen with increased width and height of the concrete slab size from $600 \mathrm{~mm} \times 650 \mathrm{~mm}$ to $750 \mathrm{~mm} \times 1050$ $\mathrm{mm}$ while maintaining the same depth of $150 \mathrm{~mm}$ to avoid cracking at the side section of the concrete rib during concrete pull-out failure. This recommendation was followed in the present experiment incorporating Multideck 60-V2, as specified in Fig. 1. The headed shear stud was placed in a favourable position by through-deck and through-hole welding with an automatic welding machine; through-deck welding was applied to a $1.2 \mathrm{~mm}$ deck, and through-hole 
welding was adopted to a $0.9 \mathrm{~mm}$ deck with a $34 \mathrm{~mm}$ diameter hole at the stud location. The diameter of the stud shank was $19 \mathrm{~mm}$, and its height was $100 \mathrm{~mm}$. An 1100-mm-long H-beam with dimensions of $350 \mathrm{~mm} \times 350 \mathrm{~mm}$ and a unit weight of $156 \mathrm{~kg} / \mathrm{m}$ was used as the steel section. A $10 \mathrm{~mm}$ diameter ribbed bar was placed on the deck shoulder for reinforcement. Table 1 and Fig. 2 present the detailed specifications of the designed specimen.

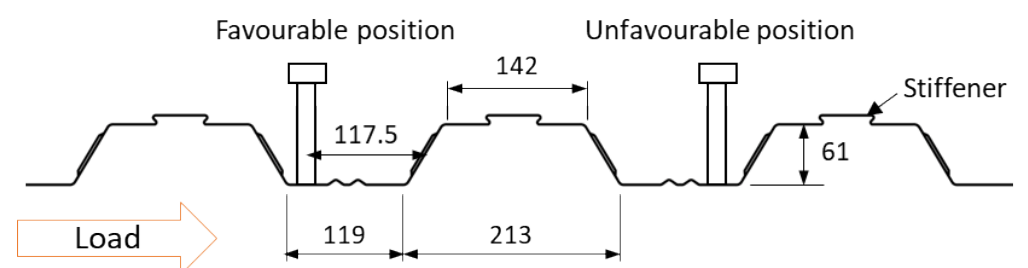

Fig. 1 Dimensions of the trapezoidal deck (Multideck 60-V2, dimensions in mm)

For the FLS testing, a customised electric furnace was prepared in accordance with the configuration of the push-out test specimen. Two furnaces were attached to each side section of the specimen, and insulation material was applied at the top and bottom surfaces of the specimen to maintain the heating condition. The ISO 834 standard fire condition was successfully demonstrated, which was verified by measuring a gas temperature at the inner space between the specimen and furnace.

Table 1 Detailed specification of the push-out test specimens

\begin{tabular}{|c|c|c|c|c|}
\hline Specimen & Test Condition & $\begin{array}{c}\text { Deck thickness } \\
{[\mathrm{mm}]}\end{array}$ & Stud welding & $\begin{array}{c}\text { Concrete strength } \\
{\left[f_{c m}, \mathrm{MPa}\right]}\end{array}$ \\
\hline T1-1 & \multirow{2}{*}{ ULS } & \multirow{3}{*}{1.2} & \multirow{3}{*}{$\begin{array}{c}\text { Through-deck } \\
\text { welding }\end{array}$} & \multirow{3}{*}{51} \\
\hline T1-2 & & & & \\
\hline T1H-1 & FLS & & & \\
\hline T2-1 & \multirow{2}{*}{ ULS } & \multirow{6}{*}{0.9} & \multirow{6}{*}{$\begin{array}{c}\text { Through-hole } \\
\text { welding }\end{array}$} & \multirow{6}{*}{32} \\
\hline $\mathrm{T} 2-2$ & & & & \\
\hline T2H-1 & \multirow{4}{*}{ FLS } & & & \\
\hline T2H-2 & & & & \\
\hline T2H-3 & & & & \\
\hline T2H-4 & & & & \\
\hline
\end{tabular}



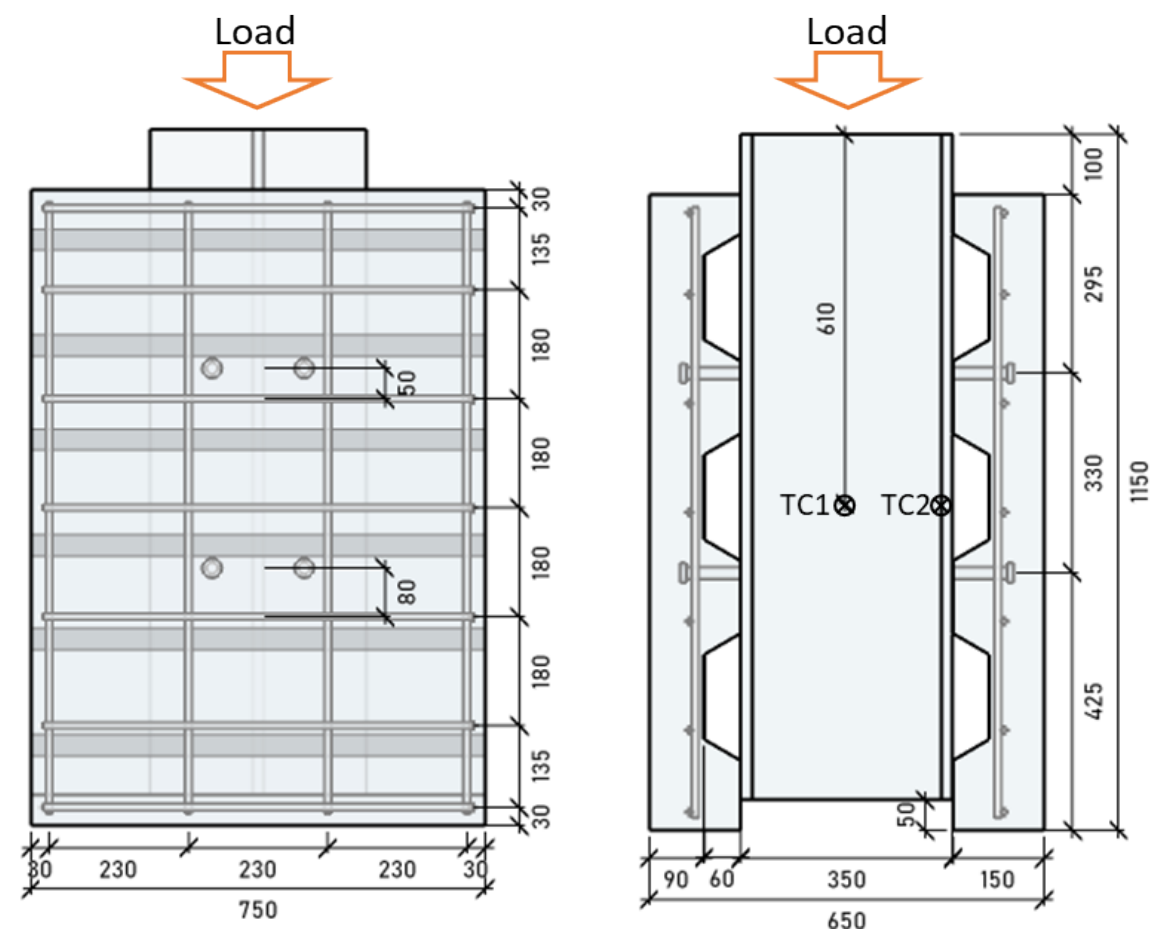

Fig. 2 Dimensions of the push-out test specimen (dimensions in $\mathrm{mm}$ )

\subsection{Materials}

Three tensile test coupons were made from the shank part of the headed shear stud. The measured average yield and ultimate stresses were $415 \mathrm{MPa}$ and $473 \mathrm{MPa}$, with an elongation of $25 \%$. A cylindrical specimen of $100 \mathrm{~mm}$ in diameter and $200 \mathrm{~mm}$ in length was prepared to evaluate the compressive strength of the concrete slab. Portland cement type I and Portland blast-furnace slag cement type II with the maximum aggregate size of $25 \mathrm{~mm}$ was used, which is composed of cement $\left(360 \mathrm{~kg} / \mathrm{m}^{3}\right)$, water $\left(162 \mathrm{~kg} / \mathrm{m}^{3}\right)$, fine aggregate $\left(835 \mathrm{~kg} / \mathrm{m}^{3}\right)$, coarse aggregate $\left(914 \mathrm{~kg} / \mathrm{m}^{3}\right)$ and admixture $\left(40 \mathrm{~kg} / \mathrm{m}^{3}\right)$. It was cured at the same condition as the push-out test specimen and tested on the first day of the experiment. The average concrete cylinder compressive strengths $\left(f_{\mathrm{cm}}\right)$ of the $1.2 \mathrm{~mm}$ and $0.9 \mathrm{~mm}$ deck specimens were $51 \mathrm{MPa}$ and $32 \mathrm{MPa}$, respectively. Concrete properties such as the characteristic compressive stress, tensile stress, and elastic modulus were calculated with reference to EC2-1-1 [17]. The yield stresses of the trapezoidal deck and rebar were $350 \mathrm{MPa}$ and $400 \mathrm{MPa}$, respectively. The yield 
and ultimate strengths of the steel beam were 345 and $490 \mathrm{MPa}$, respectively.

\subsection{Test procedure and instruments}

The push-out test procedure at ULS followed the Eurocode guidance, which provides a cyclic loading phase and load measurement range. After the initial cyclic loading, a displacement load was applied to the top of the steel beam until the induced load decreased by $20 \%$ of the maximum experienced load. The induced load and slippage were achieved with this procedure. For the push-out test at FLS, a constant load was initially induced during the entire heating process following the ISO 834 standard fire condition. The constant load was set to 20\% to $60 \%$ of the calculated shear resistance by EC4-1-1 [5]. Although the fire exposure time and

\section{slippage were recorded, this procedure closely simulates a fire condition.}

The load-bearing capacity, displacement, and temperature were measured during the pushout tests. The load was applied to the top of the steel beam through a square plate swivel jig which was connected to an actuator with a maximum capacity of $2500 \mathrm{kN}$. Linear variable differential transformers (LVDTs) were installed to measure the displacement variations in the vertical and lateral directions, as illustrated in Fig. 3. The relative displacements between the swivel jig and concrete slab were obtained with LVDT 1 and 2 . The web and flange temperatures were measured with a k-type thermocouple that was welded to the steel beam; the location details are presented in Fig. 2. The k-type thermocouple was also installed at the 


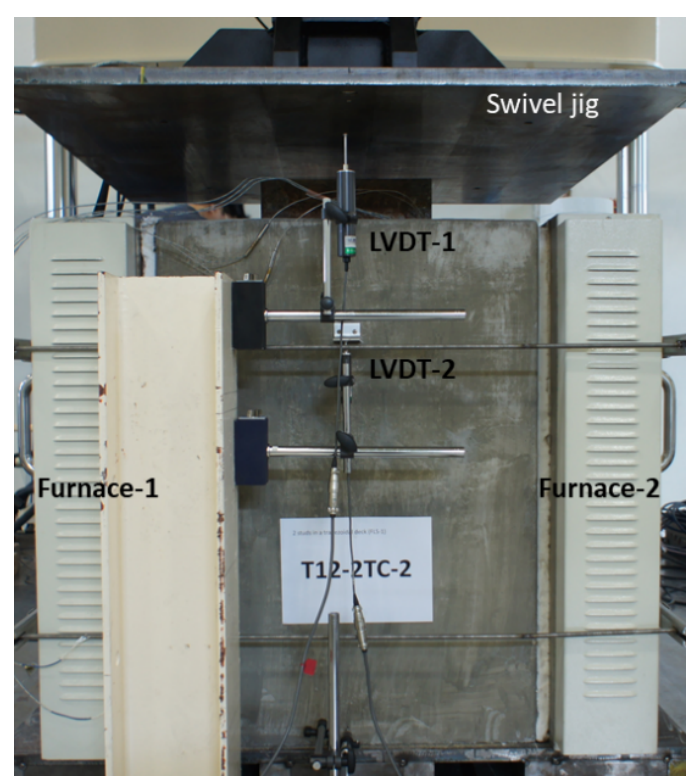

Fig. 3 Furnace and LVDT installations for the high-temperature experiment

\section{Experimental results}

\subsection{Temperature distribution}

The fire situation was established according to the specification of the ISO 834 standard fire. The gas temperature rapidly increased initially and then gradually after approximately 10 min of heating. As shown in Fig. 4, the gas temperatures are strongly correlated with the ISO 834 fire curve. The temperature distributions of the web and flange also show similar trends regardless of the welding method and deck thickness.

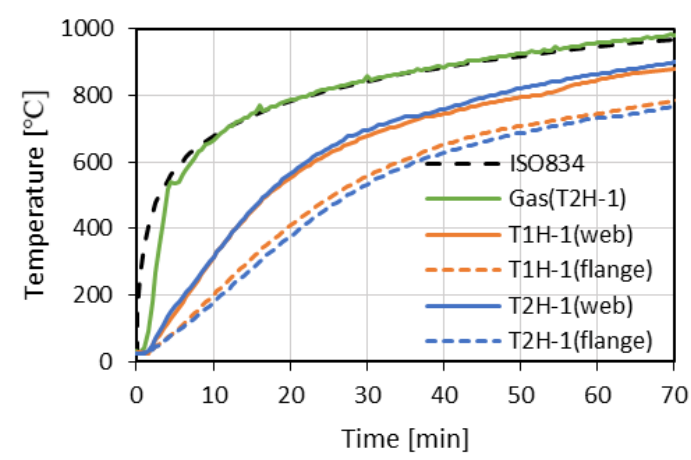

Fig. 4 Temperature distributions at high-temperature push-out tests 


\subsection{Shear resistance}

Two types of specimens were used to investigate the stud behaviour at ULS with the 1.2 $\mathrm{mm}$ and $0.9 \mathrm{~mm}$ trapezoidal decks, and their average resistances were $129 \mathrm{kN}$ and $87 \mathrm{kN}$. The results of the push-out test showed similar shear resistances, whereas the slip at the peak load differed. This slip difference may have been due to the heterogeneous properties of concrete because the same failure mode of concrete pull-out was observed in all the push-out tests.

A negative slip was observed in the high-temperature push-out test, which indicates that the force caused by thermal expansion was greater than the applied load. The negative slip constantly increased from the beginning of the heating process and gradually decreased around the maximum negative slip. The slip value rapidly changed from the negative to the positive direction at fracture accompanied by stud shearing failure.

Table 2 compares the collected shear resistances with the analytical calculations of EC4-1$1[5]$. The characteristic shear resistance $\left(P_{e, R k}\right)$ was calculated to have a $10 \%$ reduction from the minimum experimental value. Eurocode [5] was observed to conservatively estimate this shear resistance because the characteristic strength formula includes a scattering factor to consider deviations among available experimental data, based on the statistical study by Roik et al. [18].

Table 2 Comparison of the shear resistances at ULS

\begin{tabular}{ccccc}
\hline Specimen & $P_{e}[\mathrm{kN}]$ & $P_{e, R k}[\mathrm{kN}]$ & $P_{E C 4, R k^{1}}[\mathrm{kN}]$ & $P_{e, R k} / P_{E C 4, R k}$ \\
\hline $\mathrm{T} 1-1$ & 130 & 115 & 102 & 1.13 \\
\hline $\mathrm{T} 1-2$ & 128 & & & 1.10 \\
\hline $\mathrm{T} 2-1$ & 90 & 75 & 68 & \\
\hline $\mathrm{T} 2-2$ & 83 & & &
\end{tabular}

${ }^{1} f_{\text {u,max }}=450 \mathrm{MPa}$ for the calculation of a trapezoidal deck 

factor is applied regardless of the failure mode. The analytical calculation of the strength reduction shows an over 2-fold difference in the $0.9 \mathrm{~mm}$ through-hole welded specimens (T2H series). For example, the shear resistance of the T2H-1 specimen was reduced to $35 \%$ and $14 \%$ of the ULS value in the experiment and EC4-1-2 [15], respectively.

Table 3 Comparison of the shear resistances at FLS

\begin{tabular}{cccccc}
\hline Specimen & $P_{e \theta}[\mathrm{kN}]$ & $\begin{array}{c}\text { Failure time } \\
{[\mathrm{min}]}\end{array}$ & Stud temp. ${ }^{1}\left[{ }^{\circ} \mathrm{C}\right]$ & $P_{e \theta} / P_{e}{ }^{2}$ & $P_{E C 4, R k, \theta} / P_{E C 4, R k}{ }^{3}$ \\
\hline $\mathrm{T} 1 \mathrm{H}-1$ & 20 & 81 & 761.3 & 0.16 & 0.13 \\
\hline $\mathrm{T} 2 \mathrm{H}-1$ & 30.4 & 78.1 & 743.4 & 0.35 & 0.14 \\
\hline $\mathrm{T} 2 \mathrm{H}-2$ & 30.4 & 76.8 & 736.9 & 0.35 & 0.15 \\
\hline $\mathrm{T} 2 \mathrm{H}-3$ & 45.6 & 56.6 & 677.1 & 0.52 & 0.23 \\
\hline T2H-4 & 45.6 & 64.1 & 691.8 & 0.52 & 0.20 \\
\hline
\end{tabular}

$192 \%$ of the flange temperature was used based on the thermal analysis ${ }^{2}$ average value of the shear resistance at ULS ( $=129 \mathrm{kN}$ for $1.2 \mathrm{~mm}$ deck and $87 \mathrm{kN}$ for $0.9 \mathrm{~mm}$ deck) 3 according to the stud shearing failure of the EC4-1-2 (2014)

\subsection{Failure modes}

The observed failure modes at ULS and FLS were completely different. Concrete pull-out failure was observed at ULS, whereas stud shearing failure occurred at FLS. Considering the heat path and thermal conductivity of steel and concrete, a stud root area exhibited a higher temperature than the adjacent concrete rib. The higher thermal degradation caused by the temperature gradient resulted in this failure mode transition.

Concrete cracking was observed around the shear stud at the cutting plane of the specimen, as shown in Fig. 5(a). The shear resistance is decided by the concrete cracking stress arising from the moment of the concrete rib at ULS. The crack initiates from the deck stiffener to the 
other side of the deck shoulder through the stud head, which means that the area of the cracking surface is affected by the configuration of the deck stiffeners in a modern trapezoidal deck.

At FLS, shearing occurred at the bottom of the weld collar in the upper-level stud (stud 1 in Fig. 5(b)), and the steel flange was peeled off the lower-level stud (stud 2). This implies that the strength of the steel material near the stud root area decides the shear resistance in a fire. As presented in Fig. 6, the shearing failure at the interlayer between the steel flange and bottom of the shear stud was also observed in the $0.9 \mathrm{~mm}$ through-hole welded specimen.

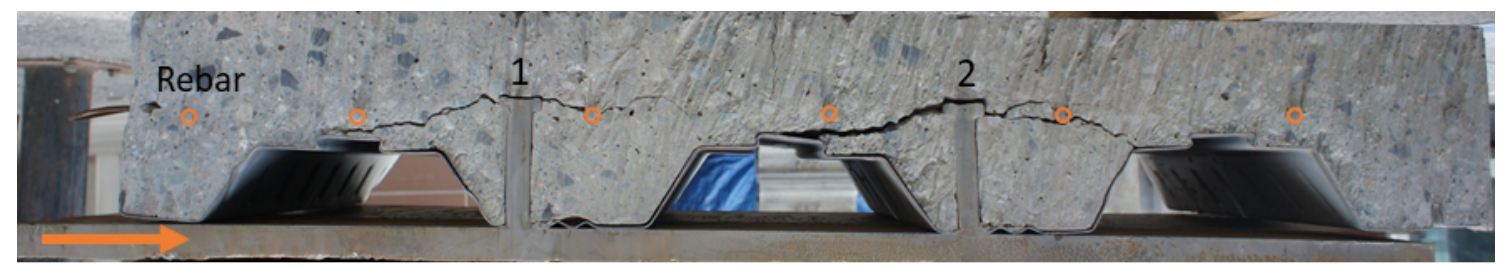

(a) Concrete pull-out failure at ULS (T1-1)
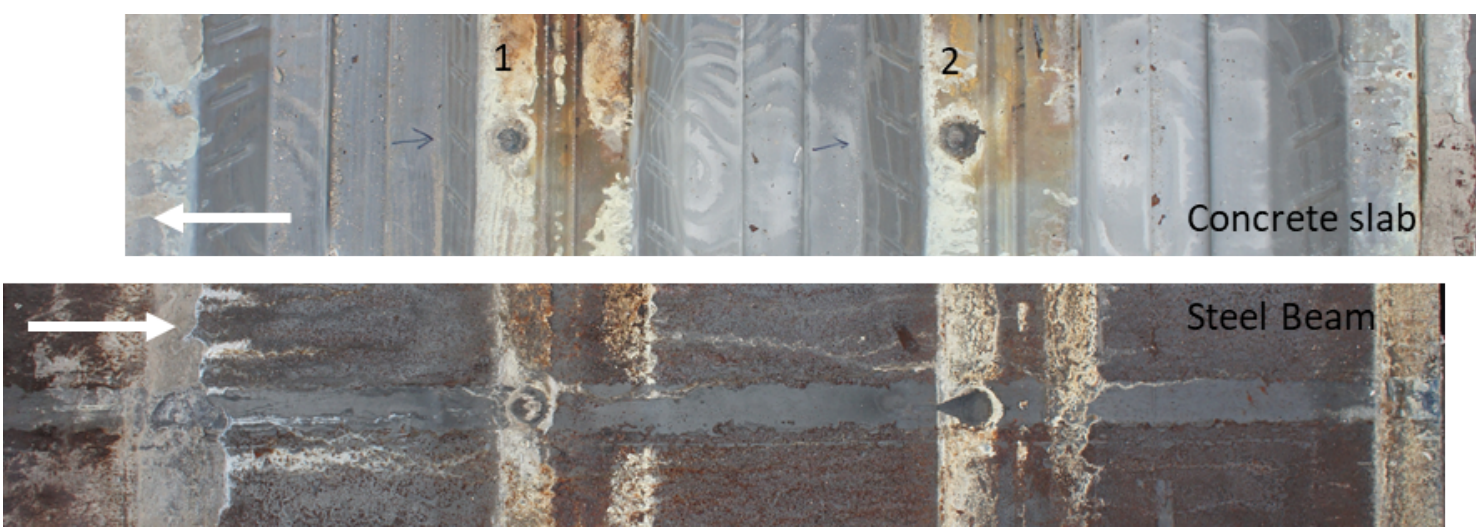

(b) Stud shearing failure at FLS (T1H-1)

Fig. 5 Failure mode of the $1.2 \mathrm{~mm}$ deck specimens
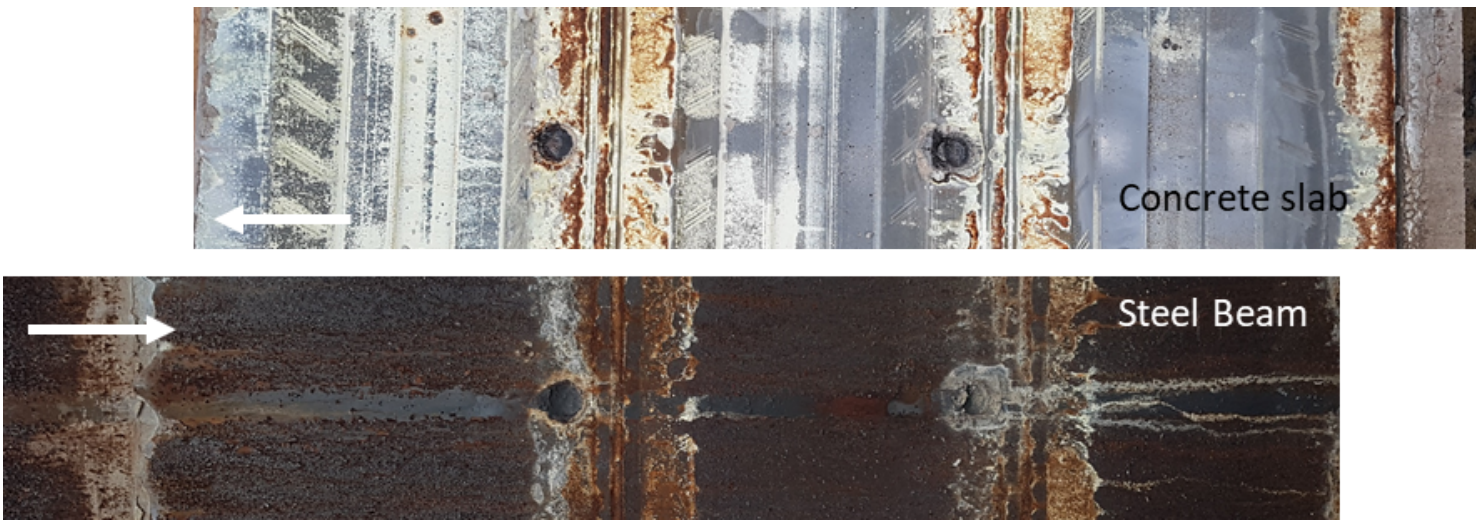

Fig. 6 Stud shearing failure of the $0.9 \mathrm{~mm}$ deck specimen at FLS (T2H-1) 


\section{Finite element model}

\subsection{Thermal model}

An eight-node linear brick element (DC3D8) was selected for the steel beam, concrete slab, and shear stud. A four-node quadrilateral shell element (DS4) and two-node link element (DC1D2) was used for the deck and reinforcement, respectively. A finer mesh was assigned to the shear stud and concrete rib because a failure occurred around that area. Material properties such as the density, specific heat, and thermal conductivity were taken from EC4-1-2 [15]. The concrete moisture was expressed with the LATENT HEAT option in Abaqus, and a 5\% moisture content was assumed. When the latent heat of the water vapour was $2.26 \mathrm{MJ} / \mathrm{kg}$, overall evaporation energy of $11.3 \times 10^{4} \mathrm{~J} / \mathrm{kg}$ was assumed to apply between 95 and $105{ }^{\circ} \mathrm{C}$ for stable calculation.

The push-out test specimen had several contact surfaces, and the applied heat was transferred through the contacting layers. The heat conduction rate depends on the geometry and deformation around the contact surfaces because of the different thermal expansion rates, spalling, and moisture evaporation [19, 20]. Ghojel [19] carried out an experimental study on the thermal conductance at a steel and concrete interface with a concrete-filled tubular column. The measured contact conductance showed a broad range of $40-225 \mathrm{~W} / \mathrm{m}^{2} \mathrm{~K}$ at $25{ }^{\circ} \mathrm{C}$ at the measurement locations, and its value decreased slightly as the temperature increased. Different thermal conductance values within the above range were used depending on the specimen type because the concrete strength and curing conditions of the specimens were different.

Heat flux was applied by convection and radiation through the inner sides of the concrete slab and steel beam. A convection coefficient of $25 \mathrm{~W} / \mathrm{m}^{2} K$ was adopted because the specimen was subjected to the ISO 834 standard fire. A configuration factor was incorporated 
to calculate the resultant emissivity according to the geometry of the push-out test setup. The emissivity of the fire and structural member was defined as 1 and 0.7 , respectively, based on EC4-1-2 [15]. The developed thermal model was validated against the measured temperature according to the fire exposure time. A strong correlation was obtained at both the web and flange temperatures, as plotted in Fig. 7.

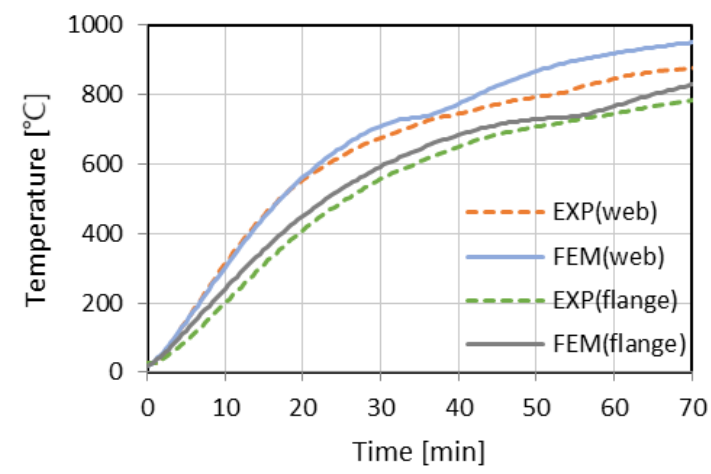

(a) T1H model (1.2 mm deck)

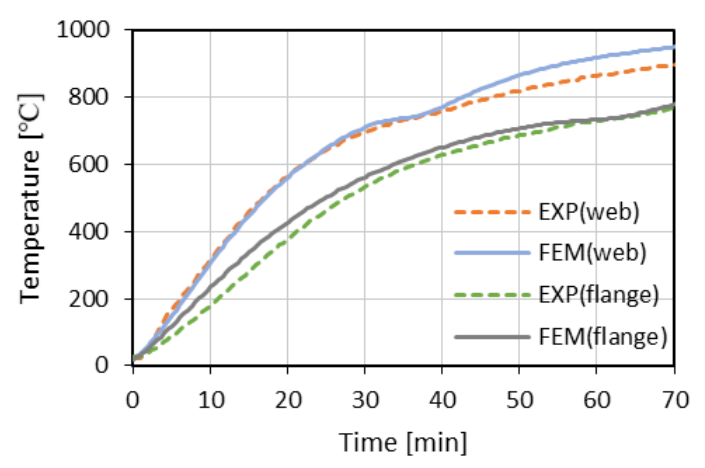

(b) $\mathrm{T} 2 \mathrm{H}$ model (0.9 mm deck)

Fig. 7 Verification of the thermal models

\subsection{Structural model}

An eight-node linear brick element with reduced integration (C3D8R) was used for the concrete slab, steel beam, and shear stud for accurate estimation. The trapezoidal deck was modelled with a four-node doubly curved thin-shell element with reduced integration (S4R). The reduced integration option decreased the computational cost and chance of shear locking. Rebar was placed in the concrete slab with a two-node linear three-dimensional truss element (T3D2) using the embedded option available in Abaqus, where the translational movement of the reinforcement node was assumed to be equal to the interpolated values of the corresponding nodes within the concrete slab.

Fig. 8 provides the finite element model with the loading surface and boundary conditions. Because of the quarter-symmetry calculation, the web of the steel beam (Surface 1) was restricted to move in the y-direction. The concrete slab, shear stud, steel beam, and transverse 
deck (Surface 2) were confined to move in the x-direction. The bottom of the concrete slab (Surface 3) was also restrained in the z-direction. A displacement load was slowly applied at the loading surface to allow quasi-static analysis with a dynamic explicit solution. The slip behaviour could be determined beyond the maximum shear resistance because it was unconditionally stable in the nonlinear analysis. A loading rate of $0.2 \mathrm{~mm} / \mathrm{s}$ was used based on the calculated natural frequency of the specimen and sensitivity analysis.

A general contact algorithm was used for all contact layers, while different contact properties were assigned. A penalty friction formulation was used for tangential behaviour. The friction coefficient between the steel and concrete is affected by experimental conditions such as the roughness of the surface, moisture content of the concrete, and contamination of the surface. Baltay and Gjelsvik [21] reported the friction coefficient at the interface of a steel plate and concrete block to be 0.47 with a nominal force range of $0-468 \mathrm{MPa}$. In the present study, a friction coefficient of 0.47 was used for the interlayers between the stud and surrounding concrete as well as between the trapezoidal deck and concrete slab. A friction coefficient of 0.2 was assumed at the bottom of the deck and steel flange. The generated friction force at the bottom of the concrete slab (Surface 3) was also considered with a friction coefficient of 0.15 . A hard contact method was used for the nominal behaviours of all contact layers except the concrete slab interfaces, for which a scale factor option available with the general contact method was adopted to control contact overclosure and stiffness.

To illustrate the through-deck welded shear stud, a tie option was used between the bottom of the stud shank (including the weld collar) and steel flange. The side section of the weld collar was also attached to the deck hole, which had the same diameter as the weld collar. The bottom of the stud shank was only tied to the steel flange in the case of the through-hole welded model. 


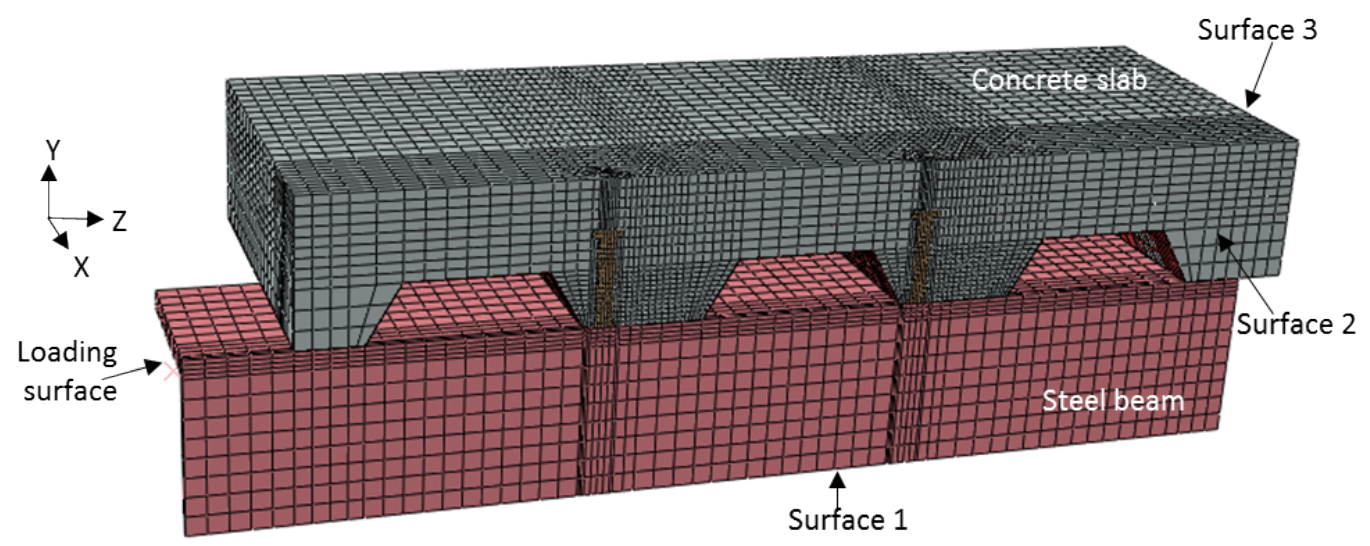

Fig. 8 Boundary conditions of the finite element model

Concrete nonlinear behaviour was simulated with a concrete damaged plasticity (CDP) model, which had four parameters to illustrate the failure surface in a multiaxial stress state. Those parameters were calculated with the equi-biaxial compressive stress ratio, deviatoric stress ratio (between the tensile and compressive meridian), and uniaxial compressive stressplastic-strain relationship. A different dilation angle and deviatoric stress ratio were used depending on the concrete strength; values of $42^{\circ}$ and 0.67 were used for $1.2 \mathrm{~mm}$ deck specimen, $50^{\circ}$ and 0.75 , for $0.9 \mathrm{~mm}$ deck specimen. The recommended values for Abaqus [22] were adopted to other plasticity parameters at ULS modelling: the eccentricity (0.1), equibiaxial compressive stress ratio (1.16) and viscosity (0). Temperature-dependent plasticity parameters were incorporated for high-temperature applications based on the plasticity parameters at ULS according to a previous numerical study [23]. The elastic modulus was calculated based on the measured compressive strength of the cylindrical concrete specimen with respect to EC4-1-2 [15], and Poisson's ratio at ULS was taken as 0.2.

The uniaxial compressive stress-strain curve and its corresponding damage function were needed to determine the cohesion stress and stiffness degradation in the CDP model. Because the compressive stress-strain relationship of EC4-1-1 [5] ends abruptly after the peak stress, the stress-strain curve recommended by EC4-1-2 [15] was used for the softening region at ULS. 
This relationship was also employed for high-temperature applications in both the ascending and descending parts. When the compressive stress was defined as less than a particular strain value, the CDP model used the same corresponding stress value beyond the specified strain value. This led to higher cohesion stress in the deviatoric stress calculation. For this reason, the compressive stress-strain curve was defined to have a higher strain value of 0.1 to obtain an accurate estimation and maintain calculation stability. An exponential function was used for a compressive damage development; refer to Lubliner et al. [24]. Typical damage values at the peak stress were $0.3-0.4$ for the uniaxial and biaxial compressive states $[25,26]$, whereas no stiffness degradation was observed in the highly confined triaxial compressive state in an experimental study by Poinard et al. [27]. The concrete beside the shear stud withstands around nine times the uniaxial compressive stress in the push-out test [28]. Thus, a damage value of 0.16 was assumed at the peak compressive stress for the numerical model.

The uniaxial tensile behaviour was regarded to have linear ascending and nonlinear descending parts, which can be expressed as an exponential function with material constants and fracture energy. The following relationship was used for the tensile softening function based on the statistical study by Hordijk [29]:

$$
\frac{\sigma_{t}}{f_{t}}=\left[1+\left(c_{1} \frac{w}{w_{c}}\right)^{3}\right] \exp \left(-c_{2} \frac{w}{w_{c}}\right)-\frac{w}{w_{c}}\left(1+c_{1}^{3}\right) \exp \left(-c_{2}\right)
$$

where $\sigma_{t}$ is the tensile stress [MPa], $f_{t}$ is the peak uniaxial tensile stress [MPa], $w$ is the cracking opening distance $[\mathrm{mm}], w_{c}=5.14 G_{f} / f_{t}, G_{f}$ is the fracture energy $[\mathrm{N} / \mathrm{mm}]$, and $c_{1}$ and $c_{2}$ are the material constants 3 and 6.93 , respectively.

The concrete fracture energy was taken from CEB-FIB90 [30], and its temperature- 
dependent values were referenced from an experimental investigation by Zhang and Bicanic [31]. The tensile strength and its thermal degradation ratio were calculated with EC2-1-2 [32]. The maximum crack opening distance at high temperatures was assumed to be $0.2 \mathrm{~mm}$ because concrete cannot withstand a tensile load when the critical crack length is exceeded. The tensile damage was defined as a function of the reduced stress from the peak tensile strength: $d_{t}=1-$ $\sigma_{t} / f_{t}$. The tensile damage also increased exponentially because of exponential softening behaviour.

The von Mises criterion was used for the nonlinear behaviour of steel materials such as the shear stud, steel beam, trapezoidal deck, and rebar. The yield and ultimate stresses were taken from the experimental data and design values specified in Section 2.2. The stress and elastic modulus of the structural steel decreased with increasing temperature. These variations were incorporated into the developed model based on the stress-strain relationships from EC3-1-2 [33]. To illustrate the stress reduction after the onset of damage, the stress triaxiality reported by Lemaitre [34] was used together with a ductile damage function. The damage function of the shear stud was calibrated with the tensile test data of the stud material. The same ductile damage function was used for all temperature ranges because the stress reduction initiates from the same strain value regardless of the temperature according to EC3-1-2 [33].

The developed finite element model was verified against the experimental results; they showed considerable agreement in terms of the shear resistance, slip capacity, and failure mode as plotted in Fig. 9. The failure mode observed in the experiment was concrete pull-out, which induced a concrete crack around the rib. When the tensile damage contour at the maximum shear resistance of the numerical model was examined, a cone-shaped crack was found as shown in Fig. 10. Greater tensile damage was observed around the lower-level stud (stud 2), and relatively little tensile damage was found between the upper-level stud and adjacent deck 
shoulder. This cracking behaviour coincided with the experimental investigation provided in Fig. 5(a). The same cause of failure was achieved in the through-hole welded specimen model. Moreover, the concrete crushed area at the bottom area of the stud shank was more significant in comparison to that of the through-deck welded model.

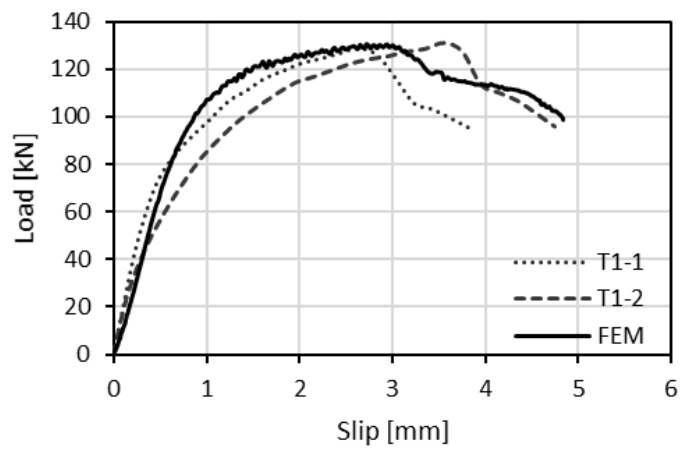

(a) $\mathrm{T} 1 \mathrm{model}(1.2 \mathrm{~mm}$ through-deck welded model)

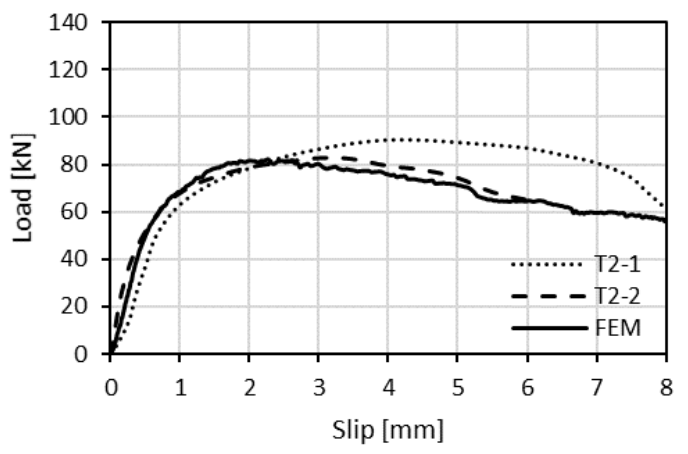

(b) T2 model $(0.9 \mathrm{~mm}$ through-hole welded model)

Fig. 9 Verification of the structural models

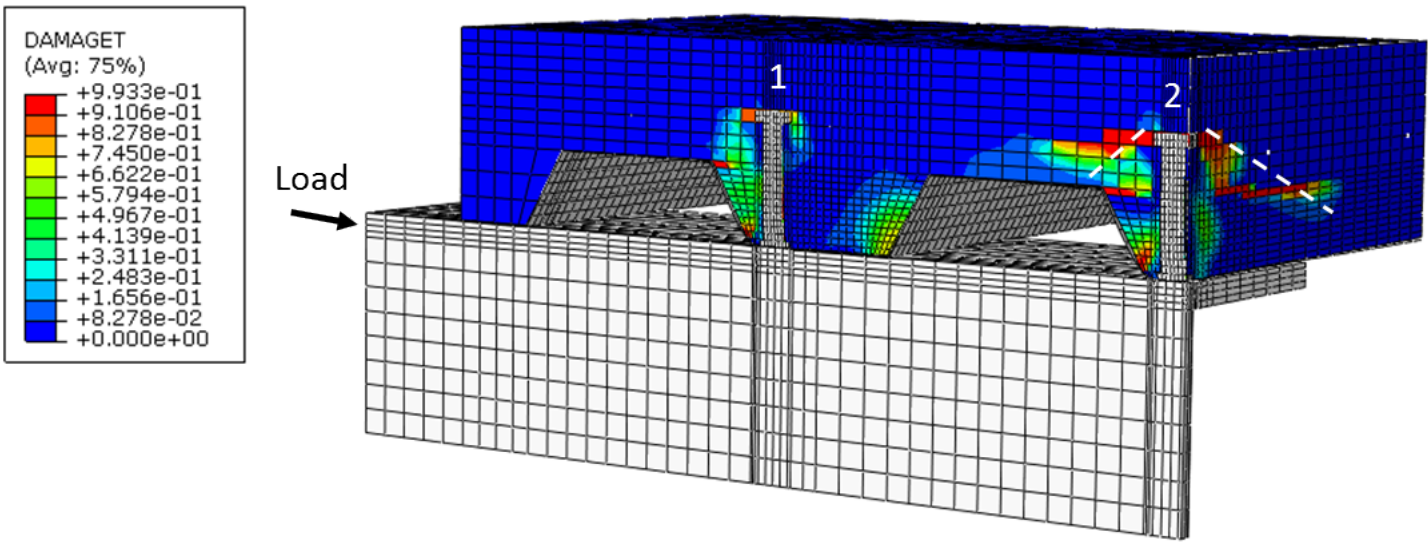

Fig. 10 Tensile damage contour at the peak load (T1 model)

\subsection{Thermomechanical model}

The developed thermal and mechanical models were combined to evaluate the structural performance of the shear studs at FLS. A constant load was initially induced to a loading 
assigned to the mechanical model with regard to the exposure time to the ISO 834 standard fire. The incorporated temperature value not only created thermal stress but also was used to define the thermal degradation of the materials. The thermal elongation properties of steel and concrete were taken from EC4-1-2 [15].

The slip variation according to the fire exposure time was collected from the hightemperature push-out test model. The numerical results agreed with the experimental data, as presented in Fig. 11: a negative displacement and sudden slip change from the negative to positive directions as the temperature increased. The top flange was sheared off after $81 \mathrm{~min}$ of heating in the $1.2 \mathrm{~mm}$ through-deck welded specimen (T1H model). This failure mode indicated that the applied thermal and mechanical loads exceeded the capacity of the thermally degraded steel section. The slip direction change required less than $1 \mathrm{~min}$ in both the experimental and numerical observations because of the rapid reduction in the shear stud strength. Stud shearing failure was also observed in the $0.9 \mathrm{~mm}$ through-hole welded specimen (T2H model). As the applied load decreased, a longer fire resistance time was observed. Thus, the thermomechanical model developed in this study successfully illustrated the shear stud behaviour during a fire in terms of the failure mode and displacement variation.

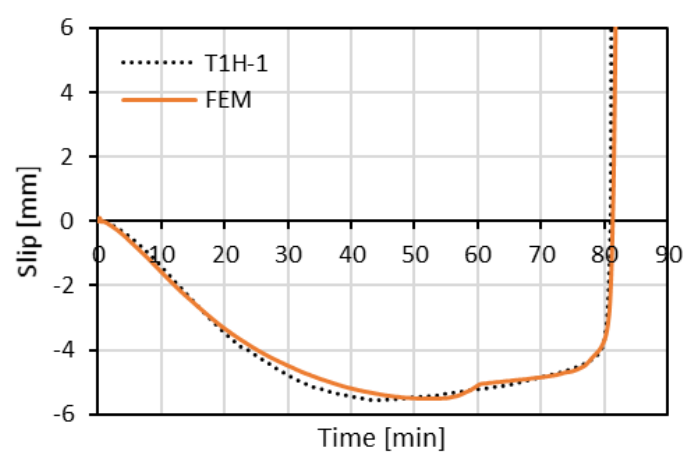

(a) T1H model (1.2 mm through-deck welding)

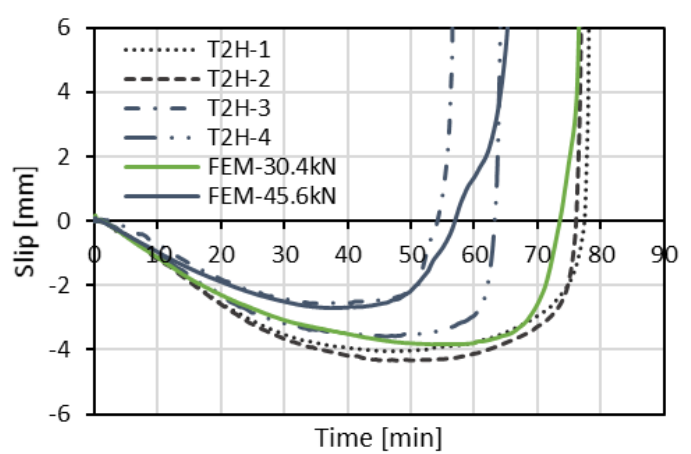

(b) T2H model ( $0.9 \mathrm{~mm}$ through-hole welding)

Fig. 11 Verification of the thermomechanical models 


\section{Parametric study and discussion}

\subsection{Effect of temperature}

The shear resistance was evaluated at different loads under the same heating condition as the ISO 834 standard fire. Table 4 presents the failure mode transition and linear relationship between the fire resistance time and shear resistance. The failure mode transition occurred between the $80 \%$ and $60 \%$ load ratio models ( $\mathrm{T} 1 \mathrm{H}$ models). The stud temperatures at fracture were 349 and $612{ }^{\circ} \mathrm{C}$ for the $80 \%$ and $60 \%$ load ratio models, respectively. Severe concrete damage was observed in the $80 \%$ load ratio model, whereas stud shearing was observed with relatively little concrete cracking when the load ratio of the shear resistance at ULS was less than $60 \%$. As the fire exposure time increased, the shear connection was governed by the thermal degradation of the stud shearing area, which shifted to the bottom of the shear stud.

The interlayer between the top side of the steel beam flange and bottom of the stud root area eventually peeled off when exposed to 74 min of the heating process (T1HR20 model), which was similarly observed in the experiment of T1H-1 specimen. An identical phenomenon was observed for the $0.9 \mathrm{~mm}$ through-hole welded models (T2H models). Severe concrete crushing and stud deformation were observed for the $80 \%$ load ratio model (T2HR80), and stud shearing occurred in the other high-temperature models.

Table 4 Parametric studies with variations in the load ratio, deck thickness, and welding method

\begin{tabular}{|c|c|c|c|c|c|c|}
\hline Model & $\begin{array}{c}\text { Deck } \\
\text { thickness } \\
{[\mathrm{mm}]}\end{array}$ & Load $[\mathrm{kN}]$ & $\begin{array}{l}\text { Load } \\
\text { ratio }^{1}\end{array}$ & $\begin{array}{l}\text { Fire resistance } \\
\text { time }[\mathrm{min}]\end{array}$ & $\begin{array}{l}\text { Stud temp. }{ }^{2} \\
\qquad\left[{ }^{\circ} \mathrm{C}\right]\end{array}$ & Failure mode \\
\hline T1HR20 & \multirow{4}{*}{1.2} & 25.8 & 0.2 & 74.0 & 801 & Stud shearing \\
\hline T1HR40 & & 51.6 & 0.4 & 51.1 & 680 & Stud shearing \\
\hline T1HR60 & & 77.4 & 0.6 & 38.0 & 613 & Stud shearing \\
\hline T1HR80 & & 103.2 & 0.8 & 17.6 & 349 & Concrete failure \\
\hline T2HR203 & 0.9 & 16.4 & 0.2 & - & - & - \\
\hline
\end{tabular}




\begin{tabular}{llllll}
\hline T2HR40 & 32.8 & 0.4 & 75.2 & 735 & Stud shearing \\
\cline { 3 - 6 } T2HR60 & 49.2 & 0.6 & 65.7 & 690 & Stud shearing \\
\cline { 2 - 5 } T2HR80 & 65.6 & 0.8 & 45.9 & 606 & Concrete failure \\
\cline { 2 - 5 } & & &
\end{tabular}

${ }^{1}$ shear strength at ULS are $129 \mathrm{kN}$ and $82 \mathrm{kN}$ for $1.2 \mathrm{~mm}$ and $0.9 \mathrm{~mm}$ deck models.

${ }^{2}$ temperature measured $5 \mathrm{~mm}$ away from the stud root.

${ }^{3}$ failure does not occur within 90 min of the heating process.
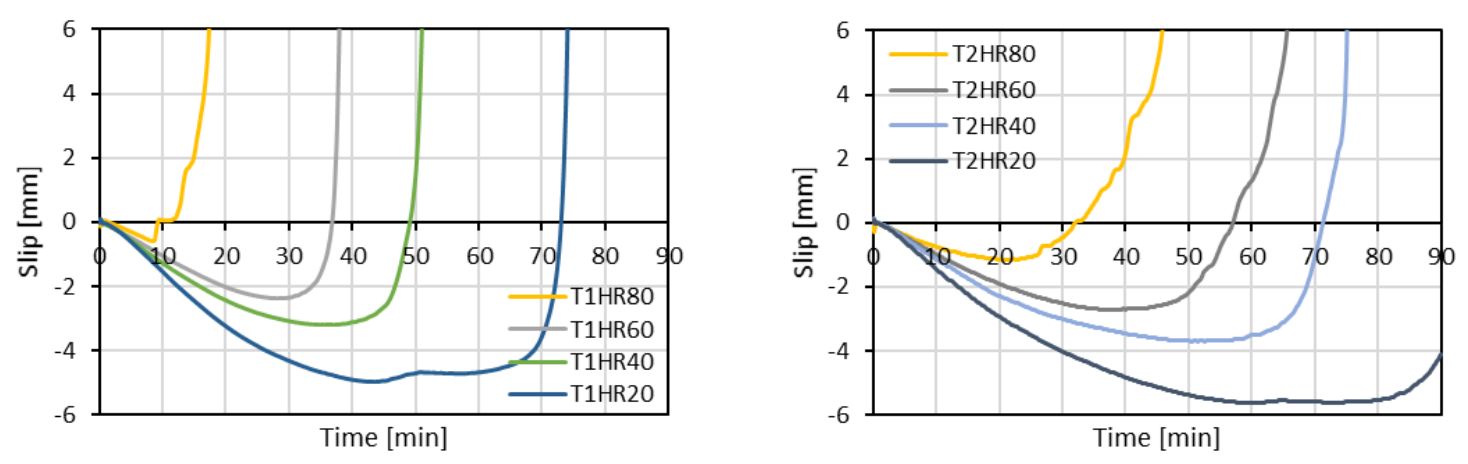

(a) $\mathrm{T} 1 \mathrm{H}$ model $(1.2 \mathrm{~mm}$ through-deck welding (b) $\mathrm{T} 2 \mathrm{H}$ model $(0.9 \mathrm{~mm}$ through-hole welding )

Fig. 12 Parametric studies with different load ratios

Fig. 13 illustrates the stress contours around the shear studs of the $1.2 \mathrm{~mm}$ through-deck welded model at the maximum negative slip. For the $20 \%$ load ratio model (T1HR20), the maximum stress formed around the weld collar in the initial stage of the heating process as in the ULS model. It changed around $40 \mathrm{~mm}$ apart from the bottom of the shear stud before fracture. This variation in the maximum stress location was due to the thermal degradation at the stud root area. In contrast, the maximum stress was created above the weld collar in the 80\% load ratio model (T1HR80), which showed a similar stress contour as the ULS model. This stress distribution induced a stronger moment at the concrete rib, which caused concrete cracking around the rib deck. The stress at the middle of the stud shank was greater than the stress at the weld collar in the less than the 60\% load ratio models, which demonstrated stud shearing failure as expected. 


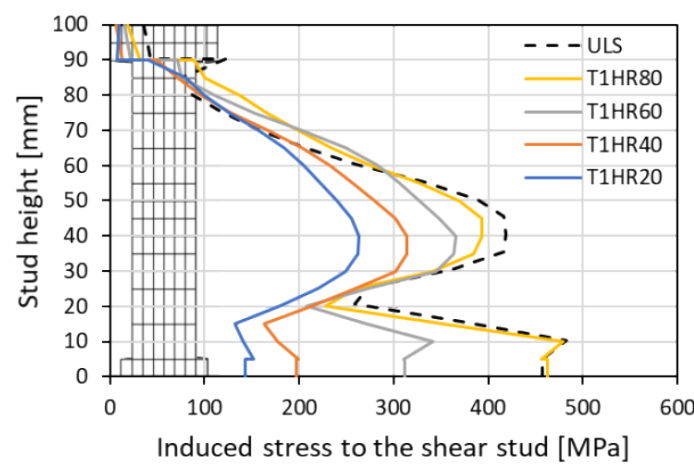

Fig. 13 Stress distributions of the shear stud at the maximum negative slip ( $\mathrm{T}$ $1 \mathrm{H}$ model)

Fig. 14 compares the shear connection capacities of two different numerical models with Eurocode 4 . The failure criterion of the stud shearing was plotted with and without the deck reduction factor: EC4(stud-solid) and EC4(stud-T2H). The concrete-dominated failure criterion followed the transverse deck calculation procedure of EC4-1-2 [15]: EC4(con-T1H) and EC4(con-T2H). The failure mode transition can be clearly observed with increasing temperature. The empty dot indicates the concrete-dominated failure, and the filled dot represents stud shearing failure. Although a sizable difference in shear resistance was observed at ULS with respect to the deck thickness, welding method, and concrete strength, the shear resistance at FLS showed a similar value accompanied by stud shearing failure. Because the deck reduction factor is included in the calculation procedure at ULS, EC4-1-2 [15] uses the same strength reduction parameter according to the temperature of the shear stud and surrounding concrete regardless of the slab type. The shear resistance can be underestimated at because the strength reduction is only decided by an empirical constant and the thermal degradation of the steel and concrete materials. The stud shearing criterion of the solid slab specimen can be appropriate for the rib deck specimen at FLS as it gives a better estimation of the transverse deck specimen than using EC4-1-2 [15]. Therefore, the failure mode should be considered to optimise the estimation of the shear resistance during a fire. 


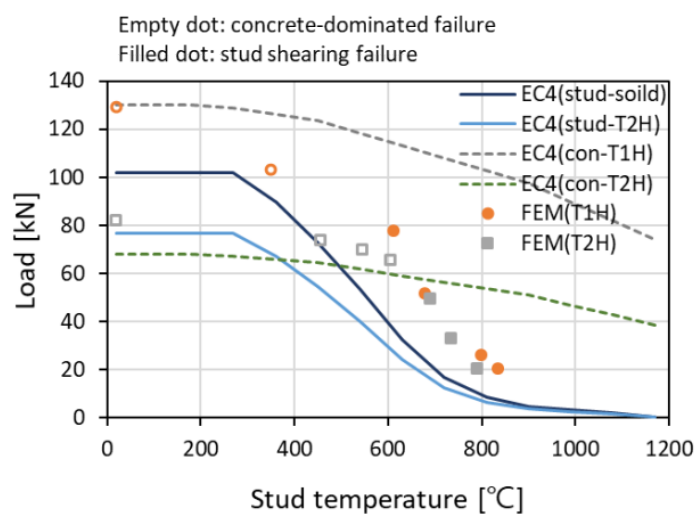

Fig. 14 Calculated shear resistance and design guidance of EC4-1-2 (2014)

\subsection{Shear resistance prediction for concrete-dominated failure}

Experimental investigations have been reported for the variation in the shear resistance with respect to temperature when headed shear studs are embedded in a transverse deck slab [

13]. If these experimental results are compared with EC4-1-2 [15], Chen et al. [13] provided a conservative value, while Mirza et al.'s [12] estimate is not conservative. These experiments used different specimen sizes and temperature profiles. Mirza et al. [12] used a $400 \mathrm{~mm} \times 400$ $\mathrm{mm} \times 120 \mathrm{~mm}$ concrete slab with the ISO 834 heating process, which resulted in concretedominated failure for all push-out tests. In contrast, Chen et al. [13] adopted a $450 \mathrm{~mm} \times 680$ $\mathrm{mm} \times 150 \mathrm{~mm}$ concrete slab with a $250 \mathrm{~mm}$ thick concrete slab base and used a slow heating process. They observed two different failure modes - concrete-dominated failure and stud shearing - as the stud temperature increased. These different failure modes were due to the different temperature distributions around the shear connections. This indicates that the shear resistance is decided by the relative temperatures of the shear stud and surrounding concrete during a fire.

A parametric study was carried out by varying the thermal conductance between the steel and concrete sections to investigate the effect of the temperature gradient around the shear 
studs. Different temperature distributions were observed around the contact layers. The stud temperature rapidly increased while the surrounding concrete temperature slowly increased when a small thermal conductance value was used between the shear studs and surrounding concrete $(\mathrm{FEM}(\mathrm{T} 1 \mathrm{H}-\mathrm{No}))$. Similarly, perfect thermal conductance reduced the temperature difference of the shear stud and surrounding concrete (FEM(T1H-Per)). Fig. 15 shows different reduction rates for the shear resistance when the concrete-dominated failure occurred, whereas an analogous estimation was obtained when the cause of failure was the stud shearing. This is a possible reason for the different experimental results in the literature [12, 13]. Consequently, a standardised test method that includes the specimen configuration and heating condition is required for consistent experimental data.

EC4-1-2 [15] defines the concrete temperature as $40 \%$ of the flange temperature for calculating the shear resistance at FLS. The thermal reduction factor is multiplied with the compressive strength of concrete to obtain the shear resistance at ULS. However, this cannot successfully estimate the shear resistance reduction caused by the concrete-dominated failure in transverse deck applications, as depicted in Fig. 15. A sizable difference in the stud temperature was observed at the same load level of $80 \%$. A new design formula for the concrete-dominated failure is proposed based on parametric studies and relevant literature that refers to the stud temperature. The maximum strength reduction was defined as $40 \%$ because the thermal degradation at the stud root area decides the load-bearing capacity below this value. 


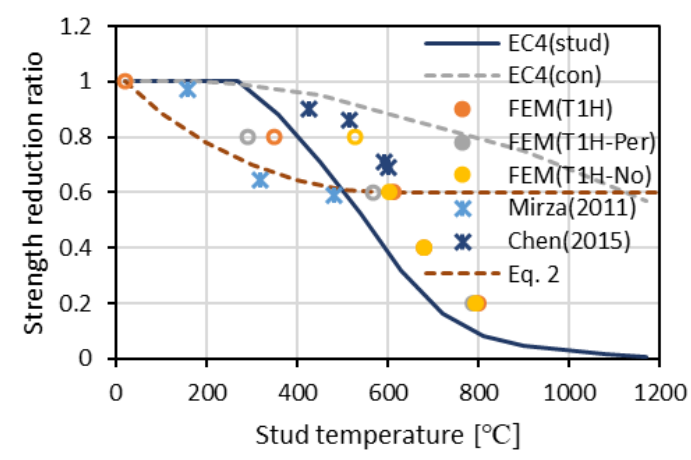

Fig. 15 Comparisons of the shear resistances with different thermal conductances

The strength reduction is expressed as follows:

$$
\begin{aligned}
& S R F_{\theta, \text { concrete }}=1 \\
& S R F_{\theta, \text { concrete }}=a \theta^{2}+b \theta+c \\
& S R F_{\theta, \text { concrete }}=0.6
\end{aligned}
$$

$$
\begin{gathered}
\theta_{\text {stud }} \leq 20^{\circ} \mathrm{C} \\
20^{\circ} \mathrm{C}<\theta_{\text {stud }} \leq 600^{\circ} \mathrm{C} \\
600^{\circ} \mathrm{C}<\theta_{\text {stud }} \leq 1000^{\circ} \mathrm{C}
\end{gathered}
$$

where $S R F_{\theta, \text { concrete }}$ is the strength reduction factor caused by the concrete-dominated failure at elevated temperatures, $a=1.17 \times 10^{-6}, \quad b=-1.39 \times 10^{-3}, c=1.012$ and $\theta_{\text {stud }}$ is the stud temperature which is defined as $90 \%$ of the flange temperature.

\subsection{Effect of trapezoidal deck thickness}

Hanswille [35] reported an upper limit value for the deck reduction factor regarding the deck thickness for calculating the shear resistance in transverse deck applications. A statistical study revealed that the shear resistance increases with a thicker deck at ULS. A parametric study with different deck thicknesses $(1.2$ and $0.9 \mathrm{~mm})$ was conducted using the through-deck welded model. Fig. 16 shows a noticeable gap in the shear resistance of the ULS and $80 \%$ load ratio models. A longer fire resistance time was observed for the $1.2 \mathrm{~mm}$ deck model than for the 0.9 mm deck model at $102 \mathrm{kN}$. The concrete-dominated failure mode caused this considerable 
difference because the thicker deck needed more stress for yielding to occur. In contrast, similar fire resistances were observed below $80 \mathrm{kN}$ because the shear resistance was decided by the thermal degradation of the stud root area. Thus, the effect of the deck thickness on the shear resistance diminishes with increasing temperature.

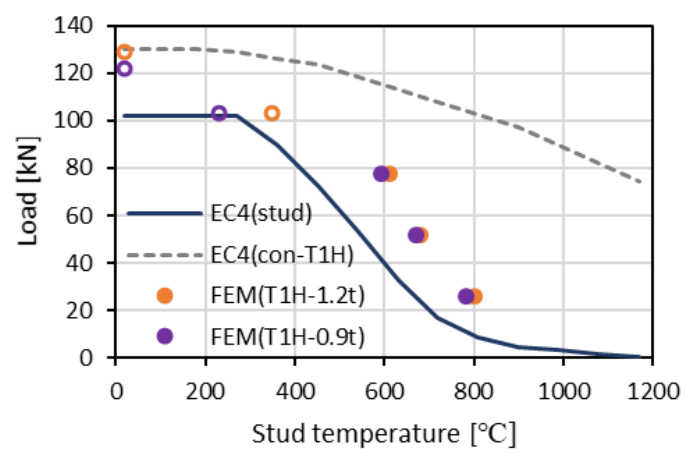

Fig. 16 Parametric studies regarding the deck thickness with the through-deck welded model

\subsection{Effect of stud welding method}

Stark and Hove [36] reported that a through-hole welded stud has a lower shear connection capacity than a through-deck welded shear stud. The stud welding method affects the shear resistance at ULS because the concrete rib is crushed when the concrete-dominated failure occurs; the through-hole welded specimen showed greater concrete crushing. Based on this experimental study, EC4-1-1 [5] provides different reduction factors according to the stud welding method for transverse deck applications. The numerical model of the $0.9 \mathrm{~mm}$ throughhole welded specimen (T2H) was modified to have a through-deck welded shear stud to investigate the effect of the welding method as temperature rises. The through-deck welded model (T2Hw) showed an increase of $20 \mathrm{kN}$ at ULS, whereas the shear resistance reached similar value at FLS, as depicted in Fig. 17. The stud shearing criterion of the solid slab (EC4(solid-stud)) conservatively estimated the modelling result when the failure mode changed to stud shearing. 
Fig. 18 illustrates the damage contours of the through-deck welded (T1HR20) and throughhole welded (T2HR40) models at a slip of $6 \mathrm{~mm}$. Although greater deck deformation was observed for the through-deck welded model, the most severely damaged area was around the stud root regardless of the stud welding method. This implies that the effect of the stud welding method decreases as temperature rises.

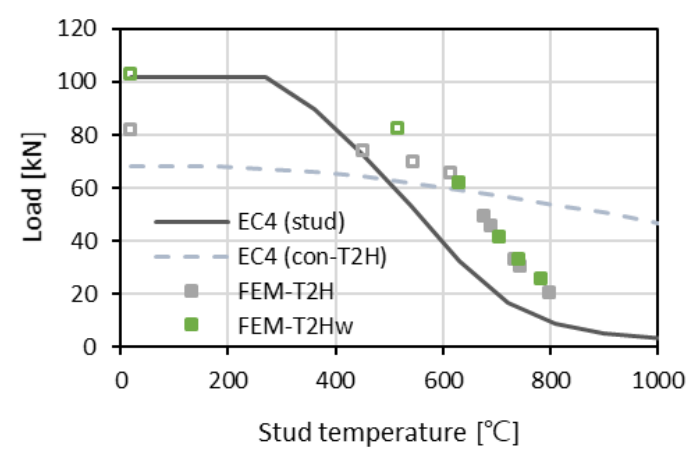

Fig. 17 Parametric studies regarding the stud welding method with the throughhole welded model

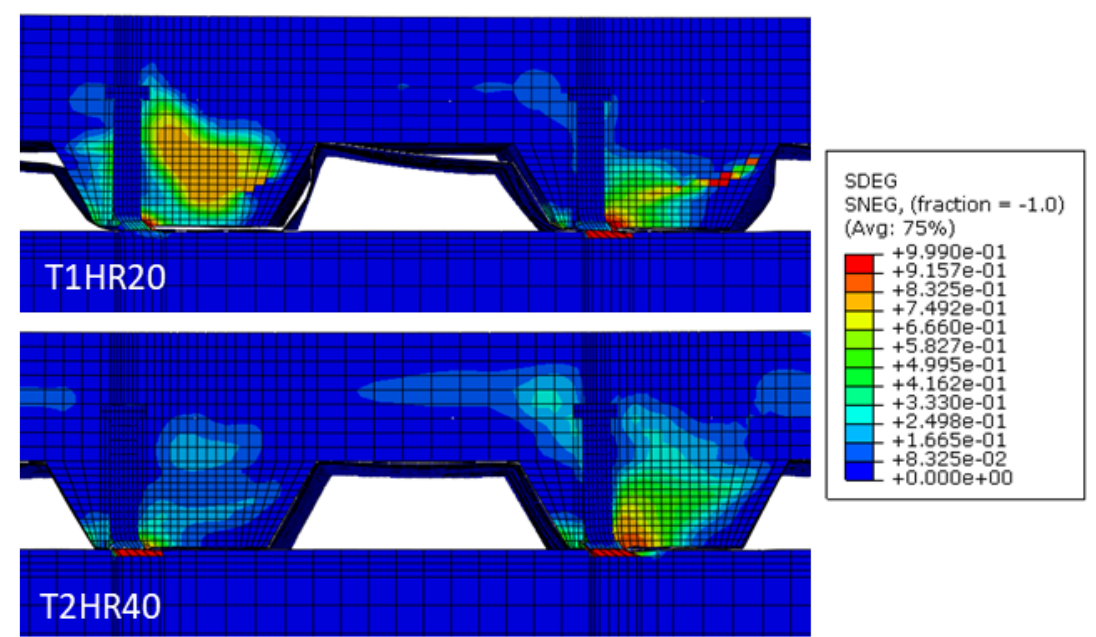

Fig. 18 Comparisons of the damage contours depending on the welding method

\section{Conclusions}

In this study, the performance of shear studs embedded in transverse decks was investigated experimentally and numerically for elevated temperatures. Nine push-out tests were conducted 
with a customised electric furnace. A three-dimensional thermomechanical finite element model was developed and verified against push-out test results at both ULS and FLS.

The shear resistance decreased as the temperature increased, and the failure mode also changed from concrete pull-out to stud shearing failure. The bottom of the stud shank and top flange near the stud root sheared regardless of the deck thickness and welding method when the stud temperature exceeded $600{ }^{\circ} \mathrm{C}$. EC4-1-2 [13] provided highly conservative estimations, especially for a through-hole welded specimen, which had a relatively small shear resistance at ULS because of the deck thickness and welding method. Omitting the deck reduction factor from the analytical calculation of EC4-1-2 [13] provided a better estimation for the transverse deck specimen when stud shearing failure occurred at FLS. Moreover, a new design formula for the concrete-dominated failure was proposed to reference the stud temperature. Both proposed design criteria can be adopted for composite beam design considering the failure mode transition in transverse deck applications.

The stress distribution of the shear stud showed the highest value around the stud root area at the beginning of the heating process. This location shifted to the stud shank as the temperature increased because of the thermal degradation of the steel material. The effects of the welding method and deck thickness decreased when the failure mode transition occurred because the thermal degradation around the stud root area became the dominant parameter in deciding the load-bearing capacity a fire.

These results provide a clear distinction for shear connection behaviour in terms of the shear resistance and failure mode both experimentally and numerically. It is expected that these observations will assist in the development of design criteria for the shear connection capacity 


\section{References}

[1] SteelConstruction.info, Cost of structural steelwork, http://www.steelconstruction.info/Cost_of_structural_steelwork. , 2017 (accessed 14 August 2017).

[2] Fisher, J. W., Design of Composite Beams with Formed Metal Deck, Eng. J. AISC 7(3) (1970) 88-96.

[3] Grant, J. A., Fisher, J. W. and Slutter R. G., Composite Beams with Formed Steel Deck, Eng. J. AISC 14 (1977) 24-43.

[4] American Institute of Steel Construction (AISC), Specification for Structural Steel Building, ANSI/AISC 360-10, Chicaga, 2010

[5] British Standard Institution (BSI), Eurocode 4 - design of composite steel and concrete structures - Part 1-1: General rules and riles for buildings, EN 1994-1-1: 2004, London, 2009.

[6] Qureshi, J., Lam, D. and Ye, J., The influence of profiled sheeting thickness and shear connector's position on strength and ductility of headed shear connector, Eng. Struct. 33 (2011) 1643-1656. https://doi.org/10.1016/j.engstruct.2011.01.035

[7] Sun, Q., Nie, X., Denavit, M. D., Fan, J. and Liu, W., Monotonic and cyclic behavior of headed steel stud anchors welded through profiled steel deck, J. Constr. Steel Res. 157 (2019) 121-131. http://dx.doi.org/10.1016/j.jcsr.2019.01.022.

[8] Nellinger, S., Odenbreit, C., Obiala, R. and Lawson, M., Influence of transverse loading onto push-out tests with deep steel decking, J. Constr. Steel Res 128 (2017) 335-353. https://doi.org/10.1016/j.jcsr.2016.08.021.

[9] Shariati, A., Shariati, M., Ramli Sulong, N. H., Suhatril, M., Arabnejad Khanouki, M. M. and Mahoutian, M., Experimental assessment of angle shear connectors under monotonic and fully reversed cyclic loading in high strength concrete, Constr Build Mater, 52 (2014), 276-283. https://doi.org/10.1016/j.conbuildmat.2013.11.036.

[10] Shariati, M., Ramli Sulong, N. H., Shariati, A. and Khanouki, M. A., Behavior of Vshaped angle shear connectors: experimental and parametric study. Materials and Structures, 49(9) (2015) 3909-3926. https://doi.org/10.1617/s11527-015-0762-8.

[11] Zhao, B. and Kruppa, J., Fire resistance of composite slabs with profiled steel sheet and of composite steel concrete beams Part 2: Composite beams, Final Report of Technical Steel Research, 1997.

[12] Mirza, O., Uy, B. and Krezo, S., Experimental studies on the behavior of headed stud shear connectors for composite steel-concrete beams under elevated temperatures, Proc. 7th International Conference on Steel \& Aluminum Structures, Kuching, Malaysia, 2011. http://dx.doi.org/10.3850/978-981-08-9247-0 rp066-icsas11. 
[13] Chen, L.-Z., Ranzi, G., Jiand, S.-C., Tahmaseninia, F. and Li, G.-Q., Behaviour and design of shear connectors in composite slabs at elevated temperatures, J. Constr. Steel Res 115 (2015) 387-397. https://doi.org/10.1016/j.jcsr.2015.08.025.

[14] International Organization for Standardization (ISO), ISO 834-1 Fire resistance tests Elements of building construction- Part 1: General requirements, Geneva, 1999.

[15] British Standard Institution (BSI), Eurocode 4 - design of composite steel and concrete structures - Part 1-2: General rules - Structural fire design, BS EN 1994-1-2: 2005, London, 2014.

[16] Hicks, S., Strength and Ductility of Headed Stud Connectors Welded in Modern Profiled Steel Sheeting, Struct. Eng. Int. 19(4) (2009) 415-419. https://doi.org/10.2749/101686609789846975.

[17] British Standard Institution (BSI), Eurocode 2 - design of concrete structures - Part 1-1: General rules for buildings, BS EN 1992-1-1: 2004, London, 2004.

[18] Roik K, Hanswille G., Cunze O. and Lanna A., Harmonisation of the European construction codes - Eurocode 2, 4 and 8/Part 3 - Report on Eurocode 4 Clause 6.3.2 Stud connectors, Report EC4/8/88. Institut fur Konstruktiven Ingenicurbau. Ruhr-UniversitatBochum, 1989.

[19] Ghojel, J., Experimental and analytical technique for estimating interface thermal conductance in composite structural elements under simulated fire conditions, Exp. Therm. Fluid Sci. 28 (2004) 347-354. https://doi.org/10.1016/s0894-1777(03)00113-4.

[20] Ding, J. and Wang, Y. C., Realistic modelling of thermal and structural behaviour of unprotected concrete filled tubular columns in fire, J. Constr. Steel Res 64 (2008) 10861102. https://doi.org/10.1016/j.jcsr.2007.09.014.

[21] Baltay, P. and Gjelsvik, A., Coefficient of friction for steel on concrete at high normal stress, J. Mater. Civil Eng. 2 (1990) 46-49. https://doi.org/10.1061/(asce)08991561(1990)2:1(46).

[22] Simulia, Abaqus 6.13 Analysis User's Guide, http://dsk.ippt.pan.pl/docs/abaqus/v6.13/index.html, 2018 (accessed 20 April 2018)

[23] Lim, O. K. and Choi, S., Numerical studies on headed shear studs under elevated temperatures, Proc. the International Conference of Applications of Structural Fire Engineering (ASFE 2017), Manchester, United Kingdom, 2017. https://doi.org/10.1201/9781315107202-27.

[24] Lubliner, J., Oliver, J., Oller, S. and Oñate, E., A plastic-damage model for concrete, Int. J. Solid Struct. 25(3) (1989) 299-326. https://doi.org/10.1016/0020-7683(89)90050-4.

[25] Lee, J. and Fenves, G. L., Plastic-damage model for cyclic loading of concrete structures, J. Eng. Mech.124(8) (1998) 892-900. https://doi.org/10.1061/(asce)07339399(1998)124:8(892).

[26] Gernay, T., Millard, A. and Franssen, J.-M., A multiaxial constitutive model for concrete in the fire situation: Theoretical formulation, Int. J. Solid Struct. 50(22-23) (2013) 36593673. https://doi.org/10.1016/j.ijsolstr.2013.07.013.

[27] Poinard, C., Malecot, Y. and Daudeville, L., Damage of concrete in a very high stress state: experimental investigation, Mater. Struct. $43 \quad$ (2010) 15-29. 
https://doi.org/10.1617/s11527-008-9467-6.

[28] Oehlers, D. J. and Bradford, M. A., Composite steel and concrete structural members fundamental behaviour, Elsevier Science Ltd, 1995.

[29] Hordijk, D. A., Local approach to fatigue of concrete, PhD. Dissertation, Technische Universiteit Delft, 1991.

[30] International Federation for Structural Concrete (FIB), CEB-FIB Model code 1990, Thomas Telford, London, 1993.

[31] Zhang, B. and Bicanic, N., Residual fracture toughness of normal- and high-strength gravel concrete after heating to $600^{\circ} \mathrm{C}$, ACI Mater. J. 99(3) (2002) 217-26. https://doi.org/10.14359/11966.

[32] British Standard Institution (BSI), Eurocode 2 - design of concrete structures - Part 1-2: General rules - Structural fire design, BS EN 1992-1-2: 2004, London, 2008.

[33] British Standard Institution (BSI), Eurocode 3: Design of steel structures - Part 1-2: General rules Structural fire design, EN 1993-1-2: 2005, London, 2009.

[34] Lemaitre, J., A Continuous Damage Mechanics Model for Ductile Fracture, J. Eng. Mater. Technol. 107 (1985) 83-89. https://doi.org/10.1115/1.3225775.

[35] Hanswille, Shear Resistance of headed Studs with Profiled Steel Sheeting, Bergische Universität Wuppertal, 1993, Technical Paper H7 to Maintenance Group for END 1994-1-1 (Eurocode: Part 1.1), 1993.

[36] Stark, J. W. B. and Hove, B. W. E. M., Statistical analysis of push-out tests in stud connectors in composite steel and concrete structures, TNO Report BI-91-163, Delft, 1991. 
Conflict of interest.

Title: Fire Performance of Headed Shear Studs in Profiled Steel Sheeting

Authors: Ohk Kun Lim, Sengkwan Choi, Sungwook Kang, Minjae Kwon, and J. Yoon Choi

The authors declare that there is no conflict of interests regarding the publication of this article. 